\title{
La moralidad kantiana y la ética de liberación de Enrique Dussel
}

Rudy Montano ${ }^{1}$

Recibido el 3 de diciembre del 2013 y aceptado el 15 de enero del 2014.

\begin{abstract}
Resumen
El artículo pretende desarrollar la crítica que Dussel realiza a la moralidad kantiana. La moralidad kantiana se fundamenta en el deber. La moralidad dusseliana se fundamenta en la vida humana del sujeto ético que vive en comunidad, con rostro concreto: la víctima, el pobre y el excluido.
\end{abstract}

Palabras claves:

Moralidad, vida, deber, totalidad, liberación

Abstract

This article aims to develop Dussel's criticism on Kant's morality. Kantian morality is based on duty to the moral law whereas Dussel bases his morality on the human life of the ethical subject, one who lives in community with a true face: the victim, the poor, and the marginalized.

Keywords:

Morality, life, duty, totality, liberation

\section{Introducción}

En este artículo se pretenden plantear dos aspectos. En primer lugar, la crítica de Dussel a la ética de la Modernidad, especialmente a la moralidad kantiana del deber. Dussel advierte que el mayor problema de la moralidad del deber es que desemboca en un esquema de Totalidad, que le quita "cuerpo" a la ética, especialmente porque se basa en el "cogito ergo sum" cartesiano, llega a la ética del deber de Kant y culmina en el espíritu absoluto de Hegel. Frente a esto, Dussel propone una corporalidad de la ética, que tiene como características dejar a un lado la absolutización del Yo y volverse al Otro, con un rostro concretado en la víctima, en el pobre, en el excluido.

1 Profesor de Antropología Filosófica en la Universidad Don Bosco. Candidato al doctorado en Filosofía Iberoamericana de la Universidad Centroamericana, José Simeón Cañas.

E-mail: rudy.montano@udb.edu.sv 


\section{Introducción: justificación del planteamiento de Dussel}

Enrique Dussel, filósofo argentino, forma parte de un grupo de pensadores que gestan una corriente de pensamiento latinoamericano llamada filosofía de la liberación, específicamente, una rama de esta denominada analéctica ${ }^{2}$. La analéctica (o ana-dialéctica) es un método alternativo al dialéctico. La dialéctica es un método que, aunque tiene sus connotaciones de cambio y se centra en las contradicciones, no supera de manera adecuada las contradicciones. Esta dialéctica desemboca en lo que Dussel llama la ontología de la Totalidad, que aunque tiene como características proyectarse hacia el otro, al hacerlo dentro de la misma Totalidad termina dominándolo. En este sentido, aunque hay una moralidad, ésta sólo consiste en promover valores que benefician a la Totalidad, no al otro. La ana-léctica, por el contrario, no depende de ninguna estructura, apunta a un futuro abierto (en el sentido de que no es un futuro propuesto por un sistema determinado) y se centra en el Otro, que tiene como rostros concretos al pobre y al excluido. El filósofo que sigue este método se convierte en una mediación que ayuda a concientizar a los pobres, a los de abajo (de ahí la expresión griega ana-lectica) a lograr su reivindicación o, como lo dice el mismo Dussel, su liberación ${ }^{3}$. Esto es lo que le da cuerpo a la ética.

\section{La ética de la Modernidad: origen y contextualización del ethos burgués ${ }^{4}$}

Dussel va a iniciar su crítica a la ética de la modernidad, enfrentándose a varios filósofos. Entre ellos aparece Inmanuel Kant, especialmente en su dimensión ética. Para Dussel, esta ética tiene como palabra clave el "deber" y su fundamento es la moralidad. Lo que interesa es qué quiere decir Kant con esa expresión o, dicho de otro modo, cómo desglosa Dussel esta propuesta de Kant para llegar a concluir que la ética kantiana es uno de los fundamentos de la ontología de Totalidad.

Dussel iniciará ubicándonos en el contexto de cambio que se gestó desde el cristianismo medieval hasta el moderno. Así mismo hablará de un "cambio de espíritu" que constituyó el cristianismo de la Europa moderna desde el s. XIV al

2 Carlos Beorlegui describe mejor esta filosofía de la liberación en la que aparecen, además de $\mathrm{E}$. Dussel, filósofos como Juan Carlos Scanonne, Osvaldo Ardiles y Humberto Ortega. Esta corriente va a tener su origen en Argentina y, posteriormente, se fue divulgando por toda Latinoamerica. Cf. C. Beorlegui, Historia del pensamiento filosófico latinoamericano. Deusto, Bilbao, 1984. págs.705757.

$3 \mathrm{El}$ tema de la ana-léctica es desarrollado ampliamente en E. Dussel. América latina. Dependencia y liberación. pp. 111-125

4 Este primer apartado está basado en E. Dussel, Para una des-trucción de la historia de la ética. pp. 74-118. 
XVII. Las notas esenciales de dicho proceso se pueden resumir en los siguientes aspectos:

a- En primer lugar se da lo que se llama una secularización de la vida. Esto quiere decir que se pasa de concebir a un hombre "religioso", es decir, dependiente de la voluntad de Dios y de la voluntad de una Jerarquía eclesiástica, a un hombre con más tinte humano, que puede razonar, que puede "estar con el siglo" (de ahí el término secularización) ${ }^{5}$. Estar con el siglo significa, precisamente, vincularse a los acontecimientos sociales, políticos, económicos, culturales y religiosos del mundo en que vive. Es un llamado a responsabilizarse con la historia, pero desde la perspectiva de la razón.

b- En segundo lugar, desde lo económico, aparecerá el espíritu burgués. Este espíritu se caracteriza por la opulencia, el lujo, el despilfarro y todos los privilegios que se le conceden a grupos económicamente poderosos de esta época.

c- Desde la perspectiva política, aparece el pensamiento del individualismo liberal, según el cual el individuo es libre, puede tomar sus propias decisiones y no necesita de un Estado que determine esas capacidades individuales que tiene.

d- Finalmente, desde la perspectiva filosófica aparece, según Dussel, la idea de un subjectum ${ }^{6}$. Esto significa que se olvida al hombre como tal, en aras de someterlo a un esquema estrictamente ontológico, de Totalidad. Hay, en consecuencia, una mayor preocupación por el "ser" del hombre, por su identidad racional, no por el hombre como tal. Esto no sólo afectará a la filosofía, sino a la ética, porque al caer esta en categorías abstractas como las del "pensamiento" y del "deber", se le quita su dimensión de corporalidad, es decir de apertura al mundo, de ver al hombre en su concretez, en su dura realidad.

5 El término secularización en este sentido, tiene la connotación de lo que se opone o es distinto a lo religioso. Es el ámbito estrictamente humano y civil.

6 Subjectum aquí tiene el sentido de querer buscar una explicación muy racional al problema del hombre, no está en el sentido griego de sub-jectum, en el sentido de buscar lo que subyace a todas las cosas. 


\subsection{Características del ethos ${ }^{7}$ burgués moderno}

Dussel, antes de desarrollar los elementos claves de la ética kantiana, pretende ubicarse en el contexto propio de la modernidad. No obstante, en este momento, no nos ubica social e históricamente, sino éticamente. Es decir, su objetivo estriba en desarrollar qué caracteriza el comportamiento ético burgués y cuáles son sus consecuencias.

En primer lugar, este ethos se caracteriza por un desinterés hacia lo divino y un interés por encontrar las estructuras que constituyen eso que llamamos el cosmos (mundo). El hombre ha llegado a la conclusión que no tenemos que buscar la explicación sobre el origen del cosmos en una especie de "luz divina", sino más bien en las estructuras mismas del cosmos. Es decir, la explicación del origen del cosmos se encuentra en el cosmos mismo. El mundo (cosmos) es ahora considerado de forma autónoma y no interesa si fue creado o no por una fuerza divina. Dios deja de ser el horizonte último de comprensión del universo y pasa a ser un "ente supremo más" que juega un papel importante en los sistemas filosóficos modernos. En Kant, especialmente, Dios sólo será el instrumento que contribuirá a dar al hombre lo que se merece por "cumplir el deber".

En segundo lugar y a consecuencia de esta preponderancia del cosmos sobre lo divino, se va a generar lo que conocemos como el capitalismo moderno, que provocará lo que Dussel denomina la objetivación del sujeto humano, es decir que el burgués capitalista no se detiene a contemplar el mundo, sino que lo ve como objeto de dominio y sometimiento. Esto implicará una acumulación de riqueza y capital, gracias a la técnica. El hombre capitalista, entonces, se convertirá en productor, ahorrador, poseedor. Desde esta perspectiva, el hombre ha sido reducido a los sistemas de producción y trabajo, que ya Dussel lo comenta cuando trabaja los planteamientos de Marx ${ }^{8}$.

Uno de los elementos característicos de la objetivación del ser humano es que este se vuelve esclavo del plan de dominio y sometimiento que tiene trazado el burgués. Es una especie de homo faber, pero sin libertad. Paralelamente a este hombre sometido, aparece el "señor burgués" que dentro de este sistema de dominación construye una serie de virtudes que tienen como

7 El término ethos viene del griego que significa carácter y también costumbre. Es decir, se hace referencia tanto a la dimensión individual de la ética, como a su dimensión normativa (mores, costumbres)

8 Este planteamiento Dussel lo elaborará en su libro La producción teórica de Marx. Un comentario a los Grundrisse. 2a edición, Siglo XXI, México, 1991. No obstante, esto no lo desarrollaré aquí, debido a que corresponde a un tema distinto al que estoy proponiendo. 
objetivo fundamental legitimar los “valores" que favorecen al sistema, pero que desfavorecen a los pobres y excluidos. Estas virtudes del dominador, se convierten en males para el dominado. ${ }^{9}$

En tercer lugar, la imagen del mundo desde el ethos burgués se construye a través de lo obvio. Esto quiere decir que los procesos del mismo sistema capitalista son tan "naturales" (obvios) que son incuestionables. Y en esa imagen del mundo que el capitalista construye aparece un proyecto propio de este tipo de burgués que tiene como características la opulencia, el lujo. Y, precisamente lo "natural" está en aceptar la realidad en la que unos pocos disfrutan de los privilegios y la mayoría vive en condiciones de pobreza.

Este nuevo ethos burgués, entonces, tiene dos connotaciones: una económica, el capitalismo; y otra política, el individualismo liberal. La palabra clave para esta connotación política es el gran valor de la libertad individual. De acuerdo a este valor, que forma parte de este nuevo ethos burgués, cada uno dispone del poder necesario para realizar lo que quiera y apropiarse de cuanto pueda. Detrás de todo esto se puede encontrar un egoísmo que consiste en procurar, a como dé lugar, el interés individual. ${ }^{10}$

Este ethos tiene como fundamento, es decir, como actitud radical y básica para la ciencia moderna, el modo mathematico. Este modo consiste en que las cosas, en cuanto ya están en el conocimiento, a lo que nos fuerzan no es a conocerlas, sino a aprender a usarlas. El ejemplo de Kant que Dussel cita es que no se aprende qué es eso que llamamos "arma", sino que se aprende a "hacer uso" de esa arma. Es asumir la actitud que todo nos estaba ya dado y lo sabemos, pero sólo nos es necesario aprender a hacer uso del mismo.

Analizando este ethos y sus características, Dussel llega a la conclusión que la consecuencia del planteamiento anterior es que el hombre deja a un lado el "ser-en-el-mundo", para dar paso a un "sujeto" que constituye, por la representación, un horizonte de objetos. Esto quiere decir que la com-prensión del ser queda reducida a la representación de objetos. Se pasa de la visión del hombre como apertura al mundo, a la concepción de la metafísica a priori del sujeto. Es en este momento en que la ética alcanza cierta independencia; no obstante, más que independencia, la ética queda como en suspenso, aun cuando sea considerada una disciplina autónoma. La ética empieza a “perder

9 Para profundizar en este tema de las virtudes de la dominación, consultar DUSSEL, E. Para una ética de la liberación latinoamericana II. Siglo Veintiuno, Buenos Aires, 1973. pp. 82ss. 10 DUSSEL, E., Para una des-trucción de la historia de la ética, op. cit. , pp. 76-82. 
cuerpo". Todo comportamiento o ethos que aparezca en el ser humano sólo puede entenderse dentro de la dimensión del sujeto.

Esta afirmación anterior tiene una implicación bastante problemática y reduccionista para el hombre: el hombre, al ser entendido como subjectum (lo racional, abstracto), cae en el peligro de entender su cuerpo como objeto, como cosa. Entonces, el mundo puede definirse como una especie de espacio vacío que es llenado con cuerpos extensos. También al afirmar esa relación sujetoobjeto, que puede desembocar en una cosificación del sujeto, se justifican las maneras en que se pueden tratar a aquellos otros sujetos distintos al sistema capitalista, dentro del cual se manifiesta este ethos burgués.

Esta nueva forma de entender al hombre como sujeto, lo reduce a mera objetualidad y lo reduce también como un proyecto representado por sí mismo para sí mismo ${ }^{11}$. Esto quiere decir que es necesario sacrificar al hombre, en beneficio del sujeto. Se va a sacrificar al hombre, como hemos dicho más arriba, como ser abierto al mundo, para darle fuerza a la afirmación que el hombre es un ser racional, pensante, pero alejado o separado de una realidad que lo interpela a diario.

\section{La ética moderna de Inmanuel Kant}

En esta dinámica de abstracción del hombre a un sujeto, aparece la reflexión que aporta Immanuel Kant que profundiza, o complica más, este problema. Sólo quiero apuntar algunos elementos que, según Dussel, influyeron en la ética del deber de Inmanuel Kant:

a- Para Dussel, Kant tuvo dos grandes momentos en su pensamiento. Arrancó primero con la ontología (el problema del ser) y posteriormente se dedicó al pensar ético. La razón de esta jerarquía es que el filósofo alemán siempre consideró que era prioritario resolver lo que él llama ontología del sujeto (la subjetividad del sujeto que pone objetividad al objeto) para después formular un pensar ético muy fundamentado.

b- Dussel considera que Kant mostró, desde el inicio, cierta independencia de su pensar. No obstante, tuvo sus bases en la escuela wolffiana y leibniziana, especialmente en lo que concierne al mundo de la naturaleza y al orden 
moral ${ }^{12}$. Al mismo tiempo, participa todavía del optimismo leibniciano ${ }^{13}$, con cierta tendencia a lo dogmático en el plano metafísico y aceptando la doctrina de la virtud. Kant no sólo se basó en sus planteamientos, sino también fue más allá de sus ideas y cuestionó sus posturas.

c- Kant tuvo también una fuerte influencia empirista ${ }^{14}$, especialmente de Hume, Schaftesbury y Hutcheson. Hume influyó en la idea que la moral sólo puede surgir del gusto y del sentimiento; Schaftesbury influyó en cuanto al deísmo secularizado y un sensualismo ético que sólo brotan de la naturaleza; Hutcheson influyó en la idea del subjectum, especialmente con la frase: el sujeto es la medida de toda moral.

d- En el proceso que lo lleva hacia la "crítica"15 pretende tomar una postura racionalista, pero sin dejar las empiristas. Acepta el dualismo platónico como fundamento antropológico y ontológico. En consecuencia, realizará una reflexión en la que establece la diferencia entre el mundo sensible y el mundo inteligible. En este proceso de reflexión, descubre que las categorías de “espacio y tiempo" son condiciones propiamente subjetivas. Dentro del mundo inteligible ubica la filosofía moral, que es conocida por el entendimiento puro ya que nos brinda los primeros principios del juicio.

La tarea de Kant, entonces, será conocer los límites del conocer sensible, del entendimiento, de la razón teórica, de la razón práctica. Dentro de esta tarea va a aparecer lo que se conoce como "filosofía trascendental" de Kant. Resumiendo, se podría decir que consiste en que el ser sólo tiene como referencia el entendimiento, que en este caso es sujeto.

Entonces, este ser se encuentra con una serie de objetos que se le presentan $y$, así descrito el ser, éste puede entenderse como un acto de la subjetividad, y en el caso del hombre, el ser, al manifestársele, sólo puede entenderse como un acto de la subjetividad humana. Por tanto, la ética sólo puede fundarse en lo que Kant llama aprioridad del sujeto. Esto quiere decir que el sujeto,

12 La influencia de Christian Wolff fue en el área de la Matemática y la de Leibniz en el área de la Física, especialmente en relación con el concepto de espacio (que Kant lo trabaja en la relación espacio-tiempo).

13 El optimismo leibniciano es la idea que Dios es tan bueno que vivimos en el mejor de los mundos posibles; Dios hace lo mejor porque puede y es bueno. Cfr. J. Marías, Historia de la Filosofía. p. 236.

14 La escuela empirista se funda en Inglaterra y tiene como afirmación fundamental que la única fuente del conocimiento está en la experiencia, es decir lo que se refiere a los sentidos. Los cuatro representantes más importantes son: John Locke, William Berkeley, David Hume y Thomas Hobbes. No obstante, el único que influyó en el pensamiento de Kant fue David Hume.

15 Este término hace referencia a la trilogía de obras de Kant: crítica de la razón pura, de la razón práctica y la crítica del juicio. 
gracias a la representación, ha abierto un ámbito trascendental de objetos. No obstante, cada objeto se encontraría inconexo, separado e inconcebible.

El filósofo argentino comienza planteando los elementos característicos de la ética kantiana para poder establecer su crítica. Lo que Dussel ha dicho hasta ahora es que Kant ve el conocimiento como algo deshistorizado, como algo fuera de la realidad. Parece que el hombre sólo tiene que buscar la verdad no en lo real y concreto sino en conceptos que son meras representaciones de los objetos. La existencia de las cosas no depende, en el fondo, de las cosas mismas, sino del sujeto que, por la representación, se acerca a las cosas. Pero para lograr tener conocimiento de esas cosas, se hace necesario tener ideas apriori, es decir, cosas que yo ya conozco de antemano, sin necesidad de recurrir a la experiencia para conocerlas.

Dussel se dedicará ahora a la tarea de establecer una crítica de esta ética kantiana. Pero para ello, planteará algunas ideas importantes que le caracterizan. En primer lugar, Kant va a sostener que modos de conocer como la ética, la teodicea, la psicología, la cosmología son los cuatro ámbitos que él denomina ideas de la razón: el alma, el mundo, Dios, y la libertad ${ }^{16}$.

La libertad es, precisamente, el culmen de la crítica de la razón pura y punto de partida de la crítica de la razón práctica. Por tanto, es piedra clave de todo el sistema. La libertad, continúa Dussel, no puede verse como objeto del conocimiento, del entendimiento porque no es una realidad fenoménica (que se nos muestra o aparece). Es más bien, una idea de la razón especulativa. La libertad es parte de la filosofía moral. No obstante, Kant deja claro que lo primero que conocemos es la ley moral que, a su vez, en ella misma se supone la libertad.

\section{1- Moralidad de Inmanuel Kant: la "crítica" de los primeros principios prácticos}

Dussel se pregunta por el fundamento de la ética filosófica kantiana. De acuerdo a Dussel, Kant buscó primero una serie de fundamentos para la ética como la teleología (relacionada con los fines), el "reino de los espíritus" (la moral bajo leyes propiamente espirituales, de conciencia), la Metodología, etc.

\footnotetext{
16 Kant se detiene a explicar esos cuatro ámbitos cuyos elementos en común estriban en que son unidad absoluta

de: sujeto pensante (alma), de la serie de condiciones del fenómeno (mundo), la condición de todos los objetos (Dios), la condición de toda moralidad (libertad). Cfr. E. Dussel, Para una destrucción de la historia de la ética, op. cit. p. 93.
} 
No obstante, se dio cuenta que, antes de buscar un fundamento, había que establecer una frontera o de-limitación de las posibilidades del saber de la razón pura práctica y sólo práctica. Esto significa separar lo que sea fundamento del saber filosófico de lo que sea fundamento de la sabiduría o fe racional. Entonces, la frontera se establece a través de una crítica de los sentimientos morales, de los conceptos y, por último de la idea de libertad.

En primer lugar, Kant va a sostener que el destino verdadero de la razón tiene que ser el producir una voluntad buena. El elemento constitutivo y a priori de toda moralidad es la "buena voluntad". Entonces, el fundamento de la moralidad del objeto de la acción, deberá ser buscada en el horizonte del mismo sujeto. Es desde esta perspectiva que se aborda el problema de la ley objetiva. Hay momentos en que esta ley no se logra cumplir sobre todo si se toman en cuenta las inclinaciones subjetivas del hombre. Se cumple cuando determina la voluntad por coacción, por obligación y se le llama mandato. Si se traduce esto al lenguaje ordinario, se puede decir que las decisiones que toma el hombre, no son fruto de su propia reflexión, sino de agentes externos, de leyes ya establecidas.

Dussel afirma que Kant cae en cierto dualismo. En primer lugar, Kant habla de lo empírico, que es reducido al egoísmo del placer y en este caso, la felicidad no puede fundar la moralidad. En segundo lugar, el fundamento tiene que pertenecer al mundo inteligible. Kant denomina a este fundamento, el subjectum. En conclusión, el fundamento de toda ley moral es el sujeto (subjectum), porque pertenece al mundo inteligible. Sin embargo, Dussel aclara que la ética kantiana no se funda en la ontología del subjectum, sino en una representación del subjectum. Entonces, al haberse ocultado el ser, se hace necesario retrotraer el fundamento a lo que ya está ontológicamente fundado y esto es lo que Kant llama la ley moral. El fundamento de toda moralidad se puede enunciar de la siguiente forma: "obra de tal manera que la máxima de tu voluntad pueda valer siempre y al mismo tiempo como principios de una legislación universal"17 Entonces, Dussel va a sostener que, de acuerdo a Kant, la síntesis a priori es una exigencia de la ontología del sujeto. Si se analiza la cita anterior, se pueden vislumbrar los siguientes elementos:

a- La importancia que cobra la experiencia: "Obra de tal manera..."

b- La valoración que la voluntad haga de la obra que se realiza y que esa valoración sea permanente: "que la máxima de tu voluntad pueda valer siempre...

17 I. Kant, Crítica de la razón práctica, p. 112. 
c- Y que esa valoración se vaya convirtiendo en "principio de una legislación universal". Esto puede significar dos cosas: decir que la legislación individual que se realiza pueda convertirse en una ley válida para todos los seres humanos y que el ser humano debe actuar en base a unos principios universales ya conocidos de antemano (a priori).

El hombre, de acuerdo al planteamiento de Kant, pertenece tanto al mundo empírico como al mundo inteligible. Por lo tanto, él tiene que realizar la síntesis de ambos ámbitos a través del objeto y del sujeto. La síntesis consiste en la voluntad afectada por el deseo (que es la máxima) con la idea de voluntad de un ser razonable (que es el principio universal). Entonces, esta ley sintética es a priori, es decir, se efectúa antes de la realización del acto y no depende de resultado alguno y tampoco de un dato empírico anterior.

Esta ley fundamental tiene como características:

- no se deduce, porque es originaria,

- además, funda todo el ámbito moral que amplía el horizonte del conocer especulativo.

El ser del objeto no puede ser según naturaleza (kata fysin), sino a partir del origen, del subjectum. Este sub-jectum es la razón de la unidad, de la síntesis. Es lo que Dussel llama "unidad unificante".

Todo lo anterior quiere decir que cuando se quiere buscar el fundamento en el sujeto, toda la moral del hombre sólo puede estar basada en aquellas dimensiones más abstractas y profundas que hay en el ser humano y que no pueden proceder del mundo en el que el hombre está inmerso.

Kant aborda el problema de la representación del objeto moral y el papel de la sensibilidad. El ámbito a tener presente es aquel que se abre desde el ser ya-dado al ser ad-viniente. Es el ámbito denominado "de las posibilidades". Estas posibilidades se descubren gracias a una com-prensión interpretativa existencial, no se inventan.

En consecuencia, es necesario hacer una distinción entre moralidad del acto y moralidad:

- la moralidad del acto, significa la coincidencia entre el ser ad-viniente y el ser-dado. Acto bueno equivale a más ser; el acto malo puede entenderse como aniquilación ontológica (la aniquilación del ser). 
- la moralidad se puede definir como una "relación" entre el acto empíricamente ejecutado y la ley universal en la constitución del objeto moral. Esto quiere decir que un acto moral sólo puede realizarse al tener presente una ley de carácter universal; sólo así se constituye el objeto moral. Por ejemplo, si una persona se dispone a "ayudar a alguien" en cualquier circunstancia, debe tomar en cuenta que, al ejecutar esa acción, está presente la ley universal "debo ayudar a los demás" y sólo de esta manera se constituye lo que Kant llama el objeto moral.

\section{- ¿Cómo se constituye el objeto moral?}

El problema que plantea Kant en este apartado es sobre los actos buenos y actos malos de todo objeto moral. El primer planteamiento que constituye el objeto moral es el siguiente: “el acto humano será bueno o malo según lo sea el objeto previamente constituido por la representación. Esta representación se efectúa por conceptos, funciones trascendentales"18. Por razón práctica, Kant entenderá la representación de un objeto como efecto (posible) de la libertad. Desde esta descripción, hay que retomar tres aspectos:

- En primer lugar, el sub-jectum (referido al sujeto humano), que se manifiesta como razón práctica (representación por concepto) y como causalidad libre, es decir como el que efectúa el acto, el efector del acto.

- En segundo lugar, el objectum que es lo que se representa por el concepto.

- En tercer lugar, la acción empírica como posible efecto de la libertad. ${ }^{19}$

Para Kant, una acción es empíricamente buena o mala si sus principios más íntimos no proceden de la experiencia, sino de la idea de la razón que determina la voluntad como fundamento a priori; es decir lo bueno o malo de un acto, depende de la representación del objeto, no antes de la ley moral, a la cual aparentemente debería servir de fundamento. Todos los conceptos morales, entonces, tienen su origen completamente a priori en la razón.

En conclusión, la ética kantiana, aunque pretende superar el pensamiento cartesiano, todavía se queda atrapada en lo abstracto, en lo teórico, en lo racional. Uno de los aspectos que demuestra lo anterior es que la moral se funda únicamente en la buena voluntad que depende del mismo sujeto para ser llevada a cabo. Otro aspecto, es creer que la moral pertenece al conocimiento inteligible y, finalmente, creer que la moral sólo tiene sentido si se concibe

18 E. Dussel, Para una des-trucción de la historia de la ética, op. cit., p. 102. 19 lbid, p. 103. 
como un "deber ser", que es el fundamento de la ley. Dussel, en su crítica, llega a una sola conclusión: la ética, desde esta perspectiva, no tiene cuerpo, no tiene lugares, personas y aspectos concretos en qué proyectarse.

\subsection{La crítica de Dussel a la moralidad de Kant}

En esta parte, se proponen algunos elementos característicos de la ética de la liberación dusseliana que además de querer superar esa visión del sujeto abstracto, centrado en el yo, quiere centrarse en el Otro, en la víctima, el excluido. Este intento se aborda de dos maneras: en primer lugar, se planteará la crítica de Dussel al planteamiento de Kant y en segundo lugar, se establecerá su propuesta a través de lo que se llama filosofía de la liberación o, específicamente, ética de liberación.

El hombre es aquel que pertenece de forma simultánea al mundo de las naturalezas puras y racionales y al mundo del cuerpo, empírico, sensible. En consecuencia, el fundamento de toda moralidad no está en el mundo sensible, sino en el mundo inteligible. Esto significa, como lo plantea Descartes, una desconfianza hacia el mundo de los sentidos. Dussel considera que lo anterior justifica una especie de dualismo en la filosofía de Kant (el mundo sensible y el mundo inteligible).

El "sujeto kantiano" es, para Dussel, en primer lugar la representación del objeto moral; la ley entonces, es el fundamento en el momento que empieza a representar como síntesis y dialéctica al objeto ${ }^{20}$. La ley es la que da el ser al objeto y el sujeto que representa es el que pone desde sí dicho ser. Como se puede ver, lo que Dussel afirma es que desde Kant, todo sujeto por obligación, está referido a un objeto. En consecuencia, el sujeto es entendido como razón práctica o voluntad. Además Kant, desde una postura dualista, afirma que el sujeto es el fundamento de la moral.

En consecuencia, Dussel plantea como fundamento de la postura de Kant lo siguiente: "El sujeto no es el hombre, ni el objeto es el mundo. No obstante, al hacer del sujeto el fundamento olvidaba que dicho fundamento es ya intramundano. Fundar la moralidad sobre la ley moral es fundarla sobre un hecho intramundano que, si fuera trascendido el sujeto como ser-en-el-mundo, se encontraría ya fundado en el ser". ${ }^{21}$

En primer lugar, poner al sujeto como fundamento es problemático porque en cierta forma la relación sujeto-objeto no significa una relación hombre-mundo. Esta relación es cerrada y solipsista y no permite la apertura del hombre al mundo, porque lo vuelve racional, abstracto.

20 E. Dussel, Para una ética de la liberación latinoamericana I, pp. 34-35

21 Ibid, p. 66 
En segundo lugar, fundar la moralidad en la ley moral quiere decir que la ley se perfila para un ámbito reducido intramundano: aquel según el cual el sujeto puede extender o desplegar al producir o constituir el objeto. Dussel afirma al respecto que esto es lo que vuelve forzosa la relación sujeto-objeto: en primer lugar el sujeto, lo único que construye en el mundo son objetos; en segundo lugar, además de forzosa es reducida en el sentido de que fundar el mundo en sujetos que constituyen objetos también limita la apertura del hombre como ser-en-el-mundo.

Dussel encuentra otro problema y es el nivel ontológico de esta reducción: el hombre como ser-en-el-mundo queda en el olvido y aparece como elemento fundamental el tema del sujeto que constituye por la representación un horizonte de objetos. Se olvida la ontología fundamental del ser en el mundo y se da fuerza a lo que Dussel llama la metafísica a priori del sujeto. ${ }^{22}$ Esto quiere decir que al constituir al hombre como sujeto este se objetiva, se cosifica y por ello, el "mundo" se considera un espacio "vacío" que puede ser llenado con cuerpos extensos. Hay un desplazamiento de esa com-prensión como descubrimiento del ser a una re-presentación del ser de forma objetivadora. En consecuencia, el hombre es considerado como aquel que es representado por mí mismo, para mí mismo; el hombre, en su dimensión mundanal queda a la deriva.

Desde la ontología, Dussel afirma que en Kant el ser no puede ser entendido como un ser adviniente; más bien el ser puede entenderse como un acto de la subjetividad humana. Si en Kant, el ser sólo puede entenderse como un acto de la subjetividad humana, su ética debe estar fundada en la aprioridad del sujeto y por lo tanto, tiene que estar fundada únicamente en sí misma. El sujeto ha abierto gracias a la representación, un ámbito trascendental de objetos, es decir la posibilidad de que esos ámbitos puedan ser conocidos. El mejor horizonte de representación que se puede tener es el de la razón. La razón tiene la función de unificar el entendimiento con la sensibilidad y esta unificación se logrará con la incorporación de todos los conocimientos adquiridos por medio de conceptos. A esto Kant llama unidad de razón. Esta serie de conocimientos, o cadena de raciocinios sólo puede darse en cuatro ámbitos importantes: en el ámbito del sujeto, para hacer que surja el concepto de alma; en el ámbito de la unión de objetos, para el concepto de mundo; en relación a la totalidad misma va a originarse la idea de Dios; y en relación a la moral, se origina la idea de libertad. Estas ideas son el ámbito de donde parten algunas ciencias como la psicología, la cosmología, la teología y la ética. 
En base a lo anterior Dussel asegura que Kant ya no puede concebir al hombre como un ser abierto al mundo; por tanto, se verá obligado a realizar un salto en el que la ética partirá de sí misma y se distanciará del mundo.

En cuanto al tema del valor en Kant, Dussel afirma que para este filósofo, los valores son puestos dentro de la relación sujeto-objeto, a tal punto que son considerados el sentido del objeto. Entonces, el valor es un momento que sólo puede fundarse en la subjetividad moderna. Dussel llega a concluir al respecto que esta relación sujeto-objeto puede considerarse un ámbito reducido del horizonte hombre-ser. El hombre no puede ser únicamente sujeto; en todo caso, esta dimensión, en el hombre, puede ser una de sus posibilidades. El problema está, de acuerdo a Dussel, en ver que si el hombre es sujeto sólo puede encontrarse ante entes que pueden ser reducidos a puros objetos y por tanto, el hombre sólo se enfrentará a estos objetos como mediaciones.

La crítica que Dussel construye al respecto sostiene que nosotros - hombres y no sujetos- en la cotidianidad, no nos enfrentamos a objetos, sino a pragmata, es decir, a útiles, a "cosas para algo". Su intento consiste en tratar de realizar la separación entre la relación del hombre con las cosas y las categorías de sujetoobjeto y centrarse en una relación que tenga como base la "com-prensión fundamental y existencial-práctico-cotidiana"23. Dussel pretende entonces, "desabstractizar" esa forma de entender la moralidad, es decir, pretende que toda moral tenga como fundamento al hombre en su relación con el "mundo de la vida" cotidiana.

El avance que se ha visto en el pensamiento de Kant, es que él no sólo se conforma con el ego cogito cartesiano, sino que queriendo ir más allá agudiza el problema del yo pienso. La agudización consiste en que el tema de la ética se inserta en la relación sujeto-objeto. Es afirmar que todo sujeto humano sólo tiene sentido si se refiere a un objeto. Este planteamiento, observa Dussel, contribuye a un mayor alejamiento de la cotidianidad, debido a que la relación sujeto-objeto y la ética como tal se construyen a través de un fundamento exageradamente abstracto. Esto quiere decir que la modernidad prefiere sacrificar la cotidianidad a costa de la absolutización de los conceptos y los elementos de su propia filosofía.

\subsection{La propuesta de Dussel: ética de la liberación}

Dussel ha escrito muchos libros y artículos en torno a la filosofía y a la ética de la liberación. En este apartado se destacarán algunos rasgos característicos 
de su ética de la liberación como respuesta a la fundamentalidad de la ética kantiana y de la modernidad en general.

a- La metafísica de la Alteridad: en primer lugar, Dussel sostiene que Kant desemboca, junto a todos los filósofos de la modernidad, en una ontología de la Totalidad. Frente a esta ontología de la Totalidad, que se caracteriza por una visión abstracta, centrada en el sujeto, se propone una metafísica de la alteridad, que quiere centrarse en el Otro como exterioridad.

La metafísica de la Alteridad ve al Otro como Otro, pero no dentro de una Totalidad, sino en su exterioridad y por eso este Otro puede entenderse como lo inexplicable, lo inabarcable, lo no - sometible a una Totalidad dominadora. El Otro, por tanto, también puede entenderse bajo la categoría de misterio porque no lo puedo conocer en su totalidad.

Entonces, el Otro puede ser visto en dos sentidos:

- Dentro de la misma Totalidad, "lo Mismo";

- Como alguien que está más allá de la Totalidad²4

El otro, a su vez, no es lo di-ferente, sino lo dis-tinto. Es lo dis-tinto porque sólo de esta forma puede entenderse en plenitud ser Otro. Este ser dis-tinto del Otro implica también que no se entiende como "lo visto", sino como "lo oído", es decir como a quien hay que escuchar.

b- Etica de la vida: Dussel maneja frecuentemente la idea de que la ética, desde América latina, es una ética de la vida, la cual se manifiesta en la relación que se produce entre la negación de la corporalidad expresada en el sufrimiento de las víctimas y la toma de conciencia de dicha negatividad: "Se parte de un "hecho empírico" de "contenido" material, de la corporalidad, de la negatividad en el nivel de la producción de la vida del sujeto humano, como dimensión de una ética material"25.

Este principio dusseliano pretende explicarse desde dos afirmaciones básicas. En primer lugar, los valores de vida buena de los poderosos, son antivalores para los pobres ${ }^{26}$. En segundo lugar, estos antivalores producen pobreza o la infelicidad de las víctimas.

24 lbid, pp. 98-108.

25 E. Dussel, Etica de la liberación en la era de la globalización y la exclusión, pp. 309-310.

26 E. Dussel, Para una ética de la liberación latinoamericana II, op. cit., pp. 85-89. 
En cuanto a los valores para los poderosos y los antivalores para las víctimas, Dussel establece varios ejemplos de los cuales se destacan dos: en primer lugar, aparece el valor o "virtud" que podría llamarse "paciencia”, que más bien es reflejo de cobardía y está a la puerta del débil. No sólo es no "poder” vengarse, sino no "querer" vengarse. En conclusión, el ethos imperante dirá Dussel, no es sino el disfraz de los vicios del oprimido como alienado. Otro ejemplo que demuestra esta inversión de valores en la Totalidad es la virtud de la fortaleza o valentía. Esta virtud encubre la violencia o potencia institucionalizada. Se vuelve violencia porque la Totalidad o la dominación quieren encubrir una debilidad presentida y un temor ante lo peligroso inminente y sin embargo desconocido (que puede estar reflejado en la víctima, en los pobres). Dicha violencia se descarga como prepotencia colérica sobre los más débiles.

Por eso, esta ética tiene un principio material: el deber ético de la reproducción y desarrollo de la vida del sujeto humano, desde una comunidad de vida ${ }^{27}$. Esto significa que se descubre un hecho masivo a finales del s. XX: la humanidad es "víctima" de profunda dominación y exclusión, encontrándose sumida en el dolor, la infelicidad, la pobreza,...etc. Esta ética, a su vez tiene relación con la economía porque la dominación es producida, fundamentalmente por el capitalismo periférico, que legitima al burgués y excluye al pobre.

c- El rostro del Otro: la víctima, el pobre, el excluido. El rostro del Otro no sólo es un término abstracto, sino que se ve reflejado en el pobre, la víctima, el excluido. Dussel plantea algunos elementos que pueden caracterizar este rostro que no sólo es latinoamericano, sino de todos aquellas regiones que sufren situaciones de exclusión.

En primer lugar, las víctimas cuestionan el sistema vigente y a todos los que legitiman el sistema vigente. Estos sistemas se han encargado de anular y negar a las víctimas a tal grado que las han reducido a no-ser. Entonces, toda ética que se considere liberadora (o de la liberación), debe optar por reivindicar a estas víctimas que han sido excluidas por el sistema dominador.

En segundo lugar, no se trata sólo de optar por las víctimas, sino que, al optar por ellas, se hace necesario ayudarles a reconocer (a tomar conciencia de) la situación en la que se encuentran para que desde ahí se puedan proponer alternativas de cambio. Es lo que Dussel llama juicio ético-crítico negativo al sistema como totalidad. 
En tercer lugar, se trata que las víctimas propongan una alternativa distinta, que les ayude a sentirse protagonistas de su historia, a mostrar una forma distinta de ejercer el poder, que no está basado en la dominación, sino en ver al Otro como otro, desde su exterioridad; en saber que ese Otro no sólo es alguien que está ahí, sino aquel a quien acompaño en todo momento, con quien me solidarizo. Esta víctima no sólo es algo abstracto, como se ha dicho antes, sino es un sujeto vivo, que camina, come, trabaja, etc. ${ }^{28}$

\section{Conclusiones}

Lo que se ha expuesto es apenas una pequeña parte del análisis que Dussel hace de la ética kantiana y las consecuencias que ha tenido para América Latina. El pretende elaborar una filosofía muy original que se adapte a nuestros contextos. De acuerdo a Dussel, una filosofía que se distancie de los contextos sociales, económicos y políticos sólo está justificando su situación de dominación y exclusión social; no es por tanto, una filosofía liberadora. Para Enrique Dussel ninguna filosofía y ninguna ética puede realizarse fuera de su contexto social, político y económico.

La crítica que Dussel realiza a la moral kantiana se centra en que la moralidad de Kant es abstracta y desemboca en una visión individualista y poco comprometida con la historia y el contexto de sus países. Frente a esto la Filosofía o ética de la liberación de Dussel propone que la moral no debe fundamentarse en elementos deshistorizados, sino en una realidad de dominación y exclusión que genera víctimas y sólo desde estas víctimas se puede empezar a elaborar una ética que tenga como aspecto fundamental, la relación del hombre con el mundo. Claro está que Dussel insta al filósofo latinoamericano a tomar la actitud de insertarse en el contexto propio de América latina para, desde ahí, poder elaborar una ética auténticamente liberadora.

Enrique Dussel hace referencia a que las víctimas y excluidos sociales son una opción fundamental para toda ética latinoamericana. No obstante, algunas izquierdas han hecho la opción por estos grupos excluidos de forma muy teórica, sin tener resonancia incluso en las mismas víctimas. Aunque se quiera aterrizar la filosofía a través de una opción clara por las víctimas, esto puede ser sólo un planteamiento abstracto y se puede caer en el peligro de que la metafísica de la Alteridad se convierta en otra Totalidad “dominadora”. Esto quiere decir dos

28 E. Dussel, Etica de la liberación en la era de la globalización y la exclusión, op. cit., pp. 314319. 
cosas: que se use a los pobres sólo como un discurso para ganar adeptos y que por tanto, este discurso sólo se quede en un nivel estrictamente académico.

Es cierto que el tema de las víctimas y los excluidos sociales parece ser algo propio de izquierdas o marxismos que, aparentemente, pasaron de moda. No obstante, la situación actual nos muestra que las víctimas, en lugar de disminuir, aumentan. Es decir, el contexto económico dominante en la actualidad nos sigue manifestando que vivimos en un contexto de pobreza y exclusión social; es decir siguen habiendo víctimas. Por tanto, se hace necesaria la intervención de una ética que ayude a las víctimas a ser conscientes de ese problema y poder salir de él. Sin embargo, parece que en la sociedad actual se ha generado una especie de actitud de cansancio e indiferencia a luchar en favor de las víctimas. $Y$ esto puede verse, tanto en las víctimas mismas, como en aquellos organismos o personas que se preocupan por ellas. El desafío es cómo rescatar este ideal de lucha y reivindicación que se ha perdido, usando métodos que se adapten a las nuevas exigencias del contexto actual.

\section{Bibliografía}

1. BEORLEGUI, Carlos,. Historia del pensamiento filosófico latinoamericano. Deusto, Bilbao, 1984.

2. DUSSEL, Enrique,

Para una des-trucción de la historia de la ética. Ser y Tiempo, Mendoza, 1972.

Para una ética de la liberación latinoamericana I. S.XXI, Buenos Aires, 1973.

Para una ética de la liberación latinoamericana II. Siglo Veintiuno, Buenos Aires, 1973.

América latina. Dependencia y liberación. Fernando García Cambeiro, Buenos Aires, 1973.

La producción teórica de Marx. Un comentario a los Grundrisse. 2a edición, Siglo XXI, México, 1991.

Ética de la liberación en la era de la globalización y la exclusión . Trotta, Madrid, 1998.

3. KANT, Immanuel,. Crítica de la razón práctica. Porrúa, México, 1992.

4. MARIAS, Julian,. Historia de la filosofía. Alianza, Madrid, 1998. 